\title{
De exilios y emociones
}

\author{
Carolina RoDRÍGUEZ-LÓPEZ \\ Universidad Complutense de Madrid \\ carolinarodriguez@ghis.ucm.es \\ Daniel Ventura Herranz \\ Universidad Complutense de Madrid \\ daventhe@gmail.com
}

Recibido: 02/06/2014

Aceptado: 12/07/2014

\section{RESUMEN}

El propósito de este artículo es probar las posibilidades que los métodos y los conceptos de la historia de las emociones plantean para un estudio renovado y profundo del exilio. Atendiendo a los ejemplos que ofrecen Américo Castro, Pedro Salinas y Fernando de los Ríos, se realiza un seguimiento, a través de sus epistolarios, de la cartografía emocional que los tres siguieron durante su proceso exílico. En los exiliados se advierte desde el comienzo sufrimiento y esfuerzo emocional, lo que les llevó enseguida a localizar sus espacios para el descanso y el refugio. Una vez que tomaron conciencia de que iban a vivir como exiliados, tocaba detectar y construir las comunidades emocionales con las que entablarían contacto para desplegar y desahogar sus emociones, pero también ubicar sus vidas, sus experiencias comunes y sus expectativas. La familia, el círculo profesional y el contacto y las referencias tanto de los colegas que se habían quedado en España como de otros tantos (españoles o no) que compartían exilo, se detectan con facilidad como esas comunidades emocionales construidas. Dilatado el proceso exílico ya plagado de vaivenes y emociones encontradas, y para vivir y no sólo sobrevivir, era obligado diseñar la propia reconstrucción emocional, una vida nueva, que no olvidaba la antigua, pero que se llenaba también de contenido y alivio.

Palabras clave: Exilio, proceso exílico, Pedro Salinas, Américo Castro, Fernando de los Ríos, sufrimiento emocional, refugio emocional, comunidad emocional, reconstrucción emocional.

\section{On exiles and emotions}

\begin{abstract}
The purpose of this article is to test the potential of the methods and concepts of the history of emotions for a renewed and deeper studying of the exile. Focused on the cases of Américo Castro, Pedro Salinas and Fernando de los Rios, the article explores through their correspondence, the emotional mapping that they followed during their exile process. In the exiles, it is warned from the start suffering and emotional stress which led them to quickly locate their spaces for rest and shelter. Once they realized they were going to live as exiles, they built emotional communities in which they deployed, vented their emotions, but also placed their lives, their common experiences and expectations. The family, the professional circle and the references from both colleagues who remained in Spain and from many others (Spanish
\end{abstract}


or not) who shared exile, are easily detected as constructed emotional communities. The exilic process was plenty of ups and downs and emotions, and to live and not just survive, the exiles were forced to design their own emotional reconstruction, their new lifes, not forgetting the old ones, but also filled with content and relief.

Key words: Exile, exile process, Pedro Salinas, Américo Castro, Fernando de los Ríos, emotional suffering, emotional refuge, emotional community, emotional reconstruction

\section{Una historia del exilio desde la perspectiva emocional. Propuesta de análisis}

Desde que Peter y Carol Stearns crearan, a mediados de los años ochenta del siglo $\mathrm{XX}$, el concepto 'emotionology', el estudio histórico de las emociones ha sido un fértil y activo work in progress. La categoría creada por los Stearns, que en principio era únicamente un intento de clarificación, no sólo reunió en un mismo haz las propuestas de estudio de lo emocional que otros historiadores habían mostrado (desde las teorías de Norbert Elias ${ }^{2}$ hasta los estudios de Philippe Ariès ${ }^{3}$, pasando por Lucien Febvre $^{4}$ ), sino que dotó a los historiadores por venir de un campo teórico sólido en el que ocuparse de las emociones. Un campo teórico sólido, pero también dinámico $\mathrm{y}$, desde luego, heterogéneo. Hechos sus cimientos con materiales procedentes de la antropología, la sociología y la psicología ${ }^{5}$, la historia de las emociones ha ido edificándose como disciplina sin olvidar una sola de sus líneas 'genéticas' y ha logrado reclamar su espacio de trabajo como método autónomo tanto en territorios ya hollados como en zonas por explorar. El exilio es al mismo tiempo un campo trabajado y un campo de exploración y, sin embargo, no se encuentra en la lista de los asuntos historiográficos abordados desde la historia de las emociones.

El propósito de este artículo es probar (en los dos sentidos de la palabra: intentar y demostrar) las posibilidades que los métodos y los conceptos de la historia de las emociones plantean para un estudio renovado y profundo de un tema ya abundan-

1 STEARNS, Peter y STEARNS, Carol Z., "Emotionology: Clarifying the History of Emotions and Emotional Standards", en American Historical Review, 90:4 (Octubre 1985), pp. 813-836

2 ELIAS, Norbert, El proceso de la civilización, México, FCE, 1988.

3 ARIĖS, Philippe, Histoire des populations françaises et de leurs attitudes devant la vie depuis le XVIIIe siècle, Self, 1948 ; ARIÈS, Philippe, L'enfant et la vie familiale sous l'Ancien régimen, Plon, 1966; ARIÈS, Philippe, L'Homme devant la mort, Seuil, 1977 y ARIÈS, Philippe y DUBY, Georges (dirs.), Histoire de la vie privée, Seuil, 1985-1987.

4 FEBVRE, Lucien, 'Sensibility and History: How to Reconstitute the Emotional Life of the Past' (1941), en BURKE, Peter (ed.), Lucien Febvre, A Niw Kind of History and Other Essays, Nueva York, 1973.

5 GEERTZ, Cliffort, The Interpretation of Cultures, Nueva York, Basic Books, 1973; ROSALDO, M., "Toward an Anthropology of Self and Feeling", en SHWEDER, R. y LEVINE, R. (eds.), Culture Theory: Essays on Mind, Self and Emotion, Cambridge, Cambridge University Press, 1984; LUTZ, C., "Emotion, Tought and Estrangement: Emotion as a Cultural Category", Cultural Anthropology, 1 (1986), pp. 405-436; GARDINER, H.N., Feeling and Emotion: A History of Theories, Westport, Greenwood Press, 1970 (1937); DIXON, Thomas, From Passions to Emotions. The Creation of a Secular Psychological Category, Cambridge, Cambridge University Press, 2003; OATLEY, Keith, Emotions. A Brief History, Blackwell Publishing, Oxford, 2004. 
temente trabajado ${ }^{6}$. Apuntamos, con todo, que el exilio como tema historiográfico precisa aún de un intenso trabajo teórico de definición y puede representar, por eso, una encrucijada metodológica poco atractiva quizás para quienes ya cargan con una?

Pero las encrucijadas no son sino un cruce de caminos y, por lo tanto, de posibilidades. Creemos que son muchas las que pueden surgir del encuentro entre el exilio y la historia de las emociones. No hace falta sino echar un vistazo a la construcción teórica que la segunda ha experimentado durante los últimos años para hallar conceptos que resultan idóneos para lidiar con algunos de los temas que los especialistas del exilio tienen en sus agendas. Es cierto que, en algunos casos, son conceptos o ideas solamente esbozados y necesitados de desarrollo y de aplicaciones prácticas para comprobar su utilidad. Pero, ¿dónde está escrito que no sea en procesos de exilio donde estos conceptos puedan ser puestos a prueba? No se trata sólo de que la disciplina esté prestando una atención predilecta a las relaciones entre la política y las emociones $^{8}$, con lo que eso tiene de interés para profundizar en el exilio como hecho político-emocional, sino de que hay en la historia de las emociones herramientas conceptuales concretas que, creemos, sirven para dar luz a aspectos de la diáspora, como la configuración de redes de exiliados, la integración socio-laboral en los países destino, las reagrupaciones familiares o la implicación política de los exiliados, entre otros muchos.

Un individuo abocado a la decisión sobre su exilio adapta una 'emoción reactiva' -si usamos el concepto de Keith Oatley ${ }^{9}$ Ya en el exilio interconecta con quienes comparten con él experiencia, como lo hacen quienes se agrupan para la batalla, el rezo, la política o la supervivencia constiyuyendo comunidades emocionales -siguiendo el concepto acuñado por Barbara Rosenwein. ${ }^{10}$ El impacto que el exilio tuvo puede cifrarse en términos de 'sufrimiento emocional' -según William Reddy- y ese sufrimiento condicionó en gran medida sus decisiones. El exilio, además, transformó a los individuos pero ellos mismos también contribuyeron a transformar su exilio: recorrieron seguramente un proceso de 'reconstrucción emocional'. Al exilio se adscribieron personas con experiencias y 'estilos emocionales' similares lo que les llevó

6 Remitimos al exhaustivo y comentado listado bibliográfico en RUIZ del ÁRBOL CANA, Antares, "Últimas aportaciones sobre el exilio español en América. La efeméride de los 70 años", Revista de Indias, 2010, vol. LXX, n 248, pp. 241-256. Añadimos los fundamentales trabajos de AZNAR SOLER, Manuel y LÓPEZ GARCíA, José Ramón (eds.), El exilio republicano de 1939 y la segunda generación, Sevilla Renacimiento, 2012 y AZNAR SOLER, Manuel (ed.), Escritores, editoriales y revistas del exilio republicano español de 1939, Sevilla, Renacimiento, 2006. También RODRÍGUEZ PUÉRTOLAS, Julio (ed.), La República y la cultura. Paz, guerra y exilio, Madrid, Istmo, 2009 y FERNÁNDEZ INSUELA, Antonio y otros (eds.), Setenta años después. El exilio literario español de 1939, Oviedo, KRK ediciones, 2010.

7 Sobre el exilio y el enfoque transnacional: RODRÍGUEZ-LÓPEZ, Carolina, «Reconsidering a Lost Intellectual Project: an Introduction», en colaboración con José M. Faraldo, en RODRÍGUEZ-LOPEZ, Carolina y FARALDO, José M. (eds.), Reconsidering a Lost Intellectual Project: Exiles' Reflections on Cultural Differences, Newcastle upon Tyne, Cambridge Scholars Publishing, 2012, pp. 1-10 y RODRÍGUEZLOPEZ, Carolina, « La emigración científica alemana en EEUU durante el III Reich. Caminos de una historia transnacional », en GALLEGO, Ferrán y MORENTE VALERO, Francisco (eds.), Rebeldes y reaccionarios. Intelectuales, fascismo y derecha radical en Europa, Barcelona, E1 Viejo Topo, 2010, pp. 213-242.

8 Véase el texto de Ute Frevert en este mismo dossier.

9 OATLEY, Keith, Emotions. A Brief History...

10 ROSENWEIN, Barbara, Emotional Communities in the Early Middle Ages, Cornell University Press, 2007. 
a compartir un mismo 'régimen emocional' ${ }^{11}$. Sólo hemos mencionado seis, pero en la gama de aportaciones conceptuales que ofrece la historia de las emociones hay muchos otros elementos susceptibles de ser usados a propósito del exilio, sin necesidad de torsiones bruscas en lo que a metodología o fuentes se refiere.

Sabemos que tras la instalación en Europa de regímenes dictatoriales de todo signo muchos ciudadanos en general y profesionales destacados, en particular, optaron por vivir en el exilio. A nosotros nos interesan los profesores universitarios españoles que impelidos por las nuevas condiciones políticas que la guerra civil (y su virtual ganador, el bando franquista), imponían, consideraron la posibilidad de vivir sus vidas (y las de sus familias) procurando una vinculación académica en los Estados Unidos (EEUU). El lector encontrará pues referidos los nombres de tres académicos españoles (Fernando de los Ríos, Pedro Salinas y Américo Castro) que desde 1936 en adelante reconstruyeron sus vidas a lo largo de un proceso exílico que se presumía corto y que acabó siendo definitivo. Los tres se enfrentaron al reto y a la obligación de reconstruir sus proyectos personales y profesionales: habían logrado huir de las depuraciones; tenían buenas oportunidades para seguir adelante con sus planes personales; descubrieron otros horizontes profesionales; alimentaron expectativas y cruzaron sus vidas con otros exiliados europeos. Desde el momento en que la opción de vivir fuera de España fue una realidad, sus vidas se llenaron de nuevas decisiones que tomar, itinerarios que emprender y cambios que asumir.

Que el proceso de exilio se iniciara debido a una decisión forzada conduce a identificar en él sin demasiado esfuerzo un buen elenco de emociones. Keith Oatley señala las correlaciones de eventos activadores, de emociones y de planes emprendidos tras la llegada de la emoción ${ }^{12}$. Si el evento motivador de la emoción tiene que ver con la consecución o con la pérdida de una meta, con la frustración por alcanzar un objetivo o con la sensación de estar ante un peligro o un conflicto de objetivos las emociones que aparecen son: felicidad, tristeza, ira y miedo. La primera emoción conduce a un compromiso mayor con el proyecto; la segunda, lleva al desinterés y a la inactividad; la tercera, a nuevos intentos renovados y la cuarta, a la paralización, al escape o al análisis de la situación. También hay eventos sociales que provocan emociones sociales. Cuando uno está con otros experimenta felicidad y sus planes son cooperar y mostrar afecto; cuando se pierde una relación la tristeza nos lleva a buscar ayuda y a fomentar nuevas relaciones; si sentimos que alguien nos insulta o nos pierde el respeto se genera en nosotros una ira que nos impulsa a pelear; si alguien nos rechaza sentimos miedo lo que nos invita a retirarnos, a irnos, a exiliarnos... Cuando tenemos cercanía física y mental con algo o alguien experimentamos amor y cuidado... Y si alguien nos amenaza sentimos desprecio y procuramos ignorarlo. Nada muy diferente a esto experimentaron los exiliados.

La capacidad exploratoria de la perspectiva emocional ${ }^{13}$ amplía las posibilidades de conocer en profundidad el proceso exílico, y de conocerlo como proceso con-

\footnotetext{
11 REDDY, William, The Navigation of Feeling. A Framework for the History of Emotions, Cambridge, 2001.

12 OATLEY, Keith, Emotions. A Brief History...

13 SIERRA, María, Género y emociones en el Romanticismo. El teatro de Bretón de los Herreros, Zaragoza, Institución Fernando el Católico, 2013.
} 
flictivo, repleto de idas, venidas y virajes físicos y emocionales. Es esa riqueza de matices la que nos ayuda a replantearnos habituales lecturas teleológicas sobre las trayectorias de los protagonistas del exilio. La vivencia del exilio fue definitiva porque obligó a las personas a desplegar nuevas habilidades vitales, a afilar su capacidad de adaptación y a reconstruirse, algo de todo punto incompatible con la evaluación de los exilios como carentes de cambios y, mucho menos, como procesos de final predecible. Los exiliados no eran personas distintas en esencia a las que eran cuando iniciaron el exilio, pero sí acabaron siendo personas nuevas, reconstruidas y formadas por las nuevas circunstancias.

Detectamos en la historiografía española dedicada a lo que se denomina generalmente 'exilio republicano' ${ }^{14}$ una relativa conformidad en la búsqueda de matices en la vida de los exiliados motivada, entendemos, por una tendencia a considerar que el camino que éstos recorrieron puede presuponerse. Se ha puesto el foco, sin embargo, en un poco constructivo (metodológica y epistemológicamente) lo que pudo haber sido y no fue, lo que España hubiera podido ser si hubieran podido seguir desarrollando sus carreras en España. El mantenimiento de esta perspectiva solo se consigue, por una parte, presumiendo y simplificando la dimensión emocional del exiliado y, por otra, esperado de él (e incluso exigiéndole) otras tantas funciones o actitudes.

Por ejemplo, que la productividad desplegada hubiera sido idéntica de haberse podido quedar en España y para siempre en las circunstancias que la República había brindado ${ }^{15}$. Suele considerarse la producción científica del exiliado fuera de España a la luz del impacto que esa misma producción hubiera tenido en España, de haberse generado aquí. Un contrafactual que se agota si vemos con detenimiento cómo y en qué circunstancias el exiliado hubo de vivir y adaptarse. Se demanda del exiliado, también, una inexcusable consciencia/participación política. Ha solido presentarse al exiliado como un permanente agente político, como una especie de depositario consciente y activo de la memoria de la España que no pudo ser y que sólo con él tenía que poder ser. Por supuesto hubo mucho de todo ello, de organización y desorganización en el exilio, de militancia y de compromiso, pero esos elementos no siempre llenaron todo el tiempo y toda la vida de los exiliados, ni siquiera de los más políticamente comprometidos o de los de manera más previsible lo estuvieron. Algunos de ellos, como de los que se ocupan Sonsoles Cabeza ${ }^{16}$, Josep Sánchez Cervelló ${ }^{17}$, Abdón Ma-

\footnotetext{
14 No es lugar este para plantear el debate sobre si resulta o no pertinente recurrir al uso del adjetivo 'republicano' para definir el exilio. Nos quedamos por ahora con la afirmación de Ángel Duarte sobre el republicanismo. Este era "en la segunda mitad del siglo XX, bajo la dictadura y en el exilio, (...) una nostalgia" y, por lo tanto, añadiríamos, una emoción más. A. Duarte, El otoño de un ideal. El republicanismo histórico español y su declive en el exilio de 1939, Madrid, Alianza, 2009, p. 372.

15 LÓPEZ SÁNCHEZ, José M., Los refugios de la derrota. El exilio científico e intelectual republicano de 1939, Madrid, CSIC, 2013. Trabajo de gran utilidad por su identificación de escenarios del exilio, del elenco de exiliados y por el apunte de sus trayectorias.

16 CABEZA SÁNCHEZ-ALBORNOZ, Sonsoles, Historia politica de la Segunda República en el exilio, Madrid, Fundación Universitaria Española, 1997.

17 SÁNCHEZ CERVELLÓ, Josep, La Segunda República en el exilio, Barcelona, Planeta, 2011.
} 
teos ${ }^{18}$ y Olga Glondys ${ }^{19}$ lo hicieron, sin duda, como lo hizo, y aquí se verá, Fernando de los Ríos, pero existe una variedad mayor de casos que permiten complejizar el proceso exílico.

Se ha presumido, igualmente, en los exiliados, una continua defensa de su nacionalidad. Una ventaja de la aproximación emocional al proceso exílico es que permite matizar mucho la imagen del exiliado como actor en la construcción de un discurso nacional y como alguien siempre enfrentado a su decisión de emigrar y obligado a manifestarse, reflexionar y decidir sobre el ser nacional. Como veremos, el sufrimiento político que el exilio produjo no se correspondió de forma automática con una militancia/participación política pero sí con una emoción que resumía el dolor de la pérdida. Salvo situaciones en las que la reflexión sobre el país dejado condujo a la parálisis o al bloqueo, el proceso exílico es más dinámico, flexible, adaptativo y fértil (vital y profesionalmente) de lo que una visión con perspectiva esencialmente nacional (o nacionalista) pudiera ofrecernos. En el exilio los individuos tuvieron por fuerza que reconstruirse emocionalmente y en ello hubo mucho también de reconstrucción nacional y de la experiencia de la nación. Como apunta Pablo Valdivia, los exiliados "they have become singularities, their works have become rare and uncomfortable for nationalisms of all sign and nature, just as rare, precious and necessary for the reassessment of the European cultural history have become academic mediations like". También en lo emocional, el exilio se configuró y desenvolvió como un fenómeno esencialmente transnacional ${ }^{20} \mathrm{y}$, por ello, transcultural ${ }^{21}$.

La aproximación emocional al exilio facilita la toma de contacto con detalles más pequeños de la vida del exiliado, con reflexiones y emociones motivadas por el mismo proceso exilíco y fraguadas en un marco cotidiano y privado. Más allá de la faceta pública del exilio (por la notoriedad y el peso de muchas de las personas que se exiliaron, las que aquí aparecerán, por ejemplo) buena parte de su dimensión emocional se vivió privada y cotidianamente. Los exiliados, en las comunidades y refugios emocionales en los que desplegaron sus sentimientos, compartieron su experiencia y dejaron constancia de detalles que permiten reconstruir su vida diaria, donde se mezclaban viejas y nuevas emociones ${ }^{22}$. En el exilio se sufría pública y políticamente pero también se vivía de veras ${ }^{23}$.

18 MATEOS, Abdón, De la guerra civil al exilio: los republicanos españoles y México: Indalecio Prieto y Lázaro Cárdenas, Madrid, Biblioteca Nueva, 2005 y MATEOS, Abdón, La batalla de México: final de la Guerra Civil y ayuda a los refugiados, 1939-1945, Madrid, Alianza, 2009.

19 GLONDYS, Olga. La guerra fría cultural y el exilio republicano español, Madrid, CSIC, 2012.

20 PATEL, Klaus Kiran, "Transnational History", en European History Online (EGO): http://www.iegego.eu/patelk-2010-en URN: urn:nbn:de:0159-20100921314 [Consultado 06/06/2014] y SIMAL, Juan Luis, "El exilio en la génesis de la nación y del liberalismo (1776-1848): el enfoque transnacional", Ayer 94/2014(2) pp. 23-48.

21 SCHMALE, Wolfgang, "A Transcultural History of Europe - Perspectives from the History of Migration", European History Online (EGO): http://www.iegego. eu/schmalew-2010a-en URN: urn:nbn:de:0159-20101011119 [Consultado 06/06/2014].

22 MEDINA-NAVASCUÉS, Tere, Memorias del exilio: la vida cotidiana de los primeros refugiados españoles en México, México, Consejo Nacional para la Cultura y las Artes, 2007.

23 La expresión se la tomamos prestada a GRACIA, Jordi, A la intemperie. Exilio y cultura en España, Barcelona, Anagrama, 2010, p. 69. 
En definitiva, con el uso preferente de la perspectiva emocional, procuramos adentrarnos en una historia del exilio desde los exiliados y nos preguntamos y les preguntamos cómo gestionaron y experimentaron sus vidas y cómo se las explicaron a sí mismos, a su entorno, a quienes compartían exilio con ellos y a los que no lo hacían. No nos interesa la historia posible ${ }^{24}$ (muy diferente, en ocasiones a aquella que ellos mismos vivían y que realmente les importaba), ni buscar en los exiliados respuestas para entender una España distinta: nos interesa la experiencia que tuvieron, no siempre la misma, a veces comparable, y siempre muy compleja y no nos interesa forzarlos a ser siempre los que eran en 1936-1939 ni a ser alguien distinto de lo que ellos, en el mismo proceso constructivo y reconstructivo, formativo y emocional, del exilio, fueron asimilando y explicando.

Las fuentes escogidas nos ayudarán en este empeño. Aquí utilizaremos los epistolarios, algunos editados y otros reconstruidos por nosotros a través de la investigación archivística. Se trata de las cartas escritas por Fernando de los Ríos, Pedro Salinas y Américo Castro, bien en su correspondencia familiar, bien en la que cruzaron con otros colegas, bien las que se intercambiaron entre ellos mismos. Los tres ubicaron su exilio en EEUU, los tres desarrollaron allí buena parte de sus vidas y los tres trabajaron, como lo hacían en España, como docentes universitarios.

Sabemos, gracias a Keith Oatley, que la conversación y la lectura (ambas cosas están en un intercambio epistolar) ponen en juego la empatía y activan mecanismos de conexión emocional que son importantes para comprender el papel que juegan las emociones en nuestras vidas. La escritura, por su parte, es otra forma de expresión emocional que, como la conversación, puede tener efectos terapéuticos a la hora de afrontar emociones negativas. La carta se transforma en un espacio idóneo para la convivencia íntima y dibuja, - como definió Janet Gurkin Altman- "las coordenadas personales -temporales, espaciales, emocionales, intelectuales- para decir a alguien en dónde estamos en un momento determinado y hasta dónde hemos viajado desde el último escrito. Los puntos de referencia de este mapa pertenecen tan solo al mundo compartido por quien escribe y quien recibe la carta: el diálogo epistolar es subrayado por los recuerdos comunes y, a menudo, por las experiencias comunes que se producen entre la escritura y las cartas" 25 .

\section{El sufrimiento y los refugios, o lo que causa el exilio}

Desde sus primeras ubicaciones, una vez fuera de España, los exiliados alimentaron diversos cauces de comunicación, las cartas preferentemente, en los que verbalizaron sus experiencias y trataron de explicar el proceso que estaban viviendo. Existen tres conceptos procedentes de la historia de las emociones que presentan una gran potencialidad para estudiar las primeras fases de los procesos exílicos: son el de $s u$ -

\footnotetext{
24 Sobre otras historias posibles BALIBREA, Mari Paz, Tiempo de exilio. Una mirada crítica a la modernidad española desde el pensamiento republicano en el exilio, Barcelona, Montesinos, 2007.

25 ALTMAN, Janet G., Epistolarity; approaches to a Form, Columbus Ohio, Ohio State U.P., 1982, p. 113. Citado en SALINAS, Pedro, Obras Completas III, epistolario, Madrid, Cátedra, 2007, p. 14.
} 
frimiento emocional, el de esfuerzo emocional y el de refugio emocional ${ }^{26}$. No hacen falta demasiadas explicaciones para ver cómo el primero de esos conceptos puede ajustarse al análisis de casos de personas obligadas a abandonar su país, dejando atrás la carrera profesional, la familia, los amigos... El sufrimiento emocional resulta evidente en los tres casos en los que vamos a centrarnos, tanto antes como en el mismo instante en que adquieren conciencia de ser desterrados.

En 1935, cuando recibió la invitación de Wellesley College para impartir clases allí durante un semestre, Pedro Salinas ya era un poeta famoso y un reputado profesor de literatura en la Universidad de Madrid. Su perfil le convertía en la persona idónea para acercar la literatura española a las alumnas de esa universidad femenina y aceptó la oferta de marcharse a partir de septiembre de 1936. Se había doctorado en 1917, había sido lector de español en las universidades de la Sorbona y de Cambridge y era catedrático desde 1917 (primero en Sevilla, luego en Murcia y finalmente en Madrid). Formó parte del Centro de Estudios Históricos (CEH) de la Junta para Ampliación de Estudios (JAE) donde se encargó de la sección de literatura moderna y fue secretario de la Universidad Internacional de verano de Santander (entre 1933 y 1936). Allí se encontraba cuando se produjo el golpe militar que provocó la guerra civil en julio de 1936, de allí salió a Francia para viajar a EEUU, como tenía previsto ${ }^{27}$.

Salinas se instaló en Nueva Inglaterra en septiembre y las primeras semanas allí, a pesar de estar separado de su familia y de saber de los episodios violentos que se daban en España, fueron de relativa felicidad. El caso de Salinas, como el de Fernando de los Ríos, resulta especialmente relevante porque la salida de España se produjo con anterioridad a la circunstancia detonante del exilio y, por supuesto, antes de tener conciencia de ser un exiliado. Hay posibilidad de contemplar en ellos, por lo tanto, el 'conflicto de metas' (Reddy) o las 'emociones reactivas' (Oatley ${ }^{28}$ ) que el exilio provoca en su emocionalidad. Esto puede contemplarse, además, de modo privilegiado en Salinas dado que escribió puntualmente a su esposa, Margarita Bonmatí, y de ella recibió noticia asidua, haciendo que lo que había comenzado como un relato detallado de la instalación en Wellesley y de la vida cotidiana en la distancia se llenara, una vez que el exilio fue consciente, de todo un repertorio de emociones negativas: primero incomprensión, luego incertidumbre, impotencia y frustración y finalmente angustia, tristeza, desesperanza e incluso ira.

Las primeras depuraciones contra los profesores izquierdistas y republicanos fueron iniciadas por el bando franquista aún durante la guerra y el nombre de Salinas junto con el de alguno de sus colegas, apareció en las primeras listas ${ }^{29}$. Es entonces cuando ese "viaje de recreo, por curiosidad espiritual" se convirtió en una "obliga-

\footnotetext{
26 REDDY, William M., The Navigation of Feeling...

27 NEWMAN, Jean Cross, Pedro Salinas y su circunstancia, Madrid, Páginas de Espuma, 2004 y LÓPEZ VIDRIERO, Ma Luisa et al., Pedro Salinas, 1891-1951, Madrid, Consorcio para la organización de Madrid capital europea de la cultura, 1992.

28 OATLEY Keith, Emotions. A Brief History...

29 Su nombre apareció referido en el BOE de 18 de agosto de 1939 cuando se confirmó su separación del servicio. CLARET MIRANDA, J. "Cuando las cátedras eran trincheras. La depuración política e ideológica en la Universidad española durante el primer franquismo", Hispania Nova, 6 (2006) (http://hispanianova. rediris.es) [Consultdo 30/06/2014].
} 
ción, en un taller" ${ }^{30}$. Un poco después, cuando la tesitura de guerra civil en España planteaba ya ásperamente la dicotomía entre regresar al caos y adentrarse en una más que posible muerte o permanecer alejado y empezar de nuevo, escribió: "¿Qué soy yo hoy? ¿Soy catedrático? (...) ¿Hay universidad? ¿La habrá? ¿Habrá España? Está uno esperando, esperando como tonto. Se cree ser lo que era, y de pronto se percibe que no se es nada. ¡Es terrible! Se quiere esconder la cabeza bajo el ala, para no ver, pero allí nos persigue la realidad terrible, ¿Qué voy a hacer?" Para el momento en que escribió esas palabras, Salinas percibía ya plenamente su circunstancia como exiliado. El dolor era muy hondo, la familia estaba lejos y en sus cartas son visibles pues la añoranza y la soledad: 'Pienso ir al Instituto de las Españas a ver a Onís, si ha vuelto ya a Nueva York y a que me diga algún sitio tranquilo donde pasar dos o tres días. La ciudad pesa demasiado, es abrumadora. Y me siento un poco solo"31, escribió en septiembre de 1936.

En cualquier caso, lo que provoca un mayor sufrimiento emocional durante los primeros meses de exilio consciente es el sentimiento de pérdida. Y no se adscribe éste solamente a lo material, aunque cunda el lamento por las fichas y las bibliotecas que quedaron atrás. En el caso de Salinas es un sentimiento de pérdida profundo y espiritual: “¿Es posible, Marg, que no vuelva a España nunca? Mira, te diré en confianza, casi en secreto que ahora que se me presenta la ocasión de pasar otro año aquí, siento como una gana íntima de irme a Europa, mejor dicho a España. Sé que es un disparate, sí, pero cuando pienso en ciertas cosas de allí, en ciertos lugares y luces (...) me dan ganas de rendirme. $¡ Y$ es tan tremenda la perspectiva del lanzamiento de una nueva vida profesional, aquí! Aún no nos damos cuenta de lo que hemos perdido. Cuando se haga la paz (i) veré que no tengo ni carrera, ni puesto, ni dinero, ni nombre, que me falta todo eso que he ganado en 40 años de vida y se ha vuelto humo. Pero que me falta, y eso es lo peor, ese algo impalpable, del aire, de la luz, del modo de hablar, de los paisajes y los cielos, que se llama España. Y nuestra casa..." 32 . Salinas era poeta y dramaturgo y la crisis creativa que llevaba aparejada el exilio es un elemento clave del sufrimiento emocional que experimentó: "Yo en Madrid, en España, podía intentarlo todo, y mi drama solo con hablar a dos amigos hubiera sido leído, acaso estrenado, por una compañía de Madrid. (...) En España mi nombre literario me abría todas las puertas; aquí no tengo nombre, sino entre unos pocos enterados de lo español. (...) Un boxeador vale lo mismo en Barcelona que en New York, y así un violinista o un aviador. Pero un poeta lírico es, para un público extranjero, un incógnito. (...) Me da pena, una pena más, ver que nada de lo que había hecho en España y que me daba cierta confianza en mí, exteriormente, queda en pie. Y hay que empezarlo todo, otra vez. Lo práctico, lo profesional, estoy animado a re-empezarlo, porque es para nosotros. Pero para mí no tengo ganas de empezar nada otra vez"33.

Sufrió también y por motivos parejos Fernando de los Ríos. Aunque se estableció en EEUU en 1936 (primero Washington D.C. y después Nueva York), sostenemos que su exilio comenzó realmente en 1939. Hasta entonces, De los Ríos había sido

30 SALINAS, Pedro, Obras Completas III..., p. 613.

31 SALINAS, Pedro, Obras Completas III..., p. 513.

32 SALINAS, Pedro, Obras Completas III..., p. 567.

33 SALINAS, Pedro, Obras Completas III..., pp. 570-571. 
el representante de un gobierno legalmente constituido; tras el hundimiento de la República, con los diferentes sectores republicanos enfrentados entre sí y con las tensas gestiones para constituir un Gobierno en el exilio, su situación era mucho más precaria, tanto en lo político como en lo económico. El Gobierno al que servía trataba de evitar la desbandada mediante una estructuración más o menos rápida fuera de España y su posición como embajador dejó de existir. A finales de marzo de 1939, dejó la Embajada de España en Washington y se instaló en Nueva York junto a su mujer Gloria Giner, su hija Laura, su madre Fernanda y su suegra Laura ${ }^{34}$. Las cartas de Fernando de los Ríos son comparativamente pocas y no son tan explícitas como las de Salinas a la hora de describir el impacto emocional del exilio. Una lectura superficial, de hecho, nos llevaría a pensar que para él, el exilio supuso solamente un cierto agobio laboral y un aumento de las preocupaciones familiares. Sólo en algunos comentarios sueltos apareció, durante la primera etapa de su exilio, el dolor adscrito al destierro. Como en esta carta que escribió a Indalecio Prieto, con quien mantuvo una intensa correspondencia, en mayo de 1939: “iTenga cuidado, Indalecio, con la banda! Se les ha exacerbado el cinismo y pretenden invertir el papel de acusados en el de fiscal. Yo he considerado, ante un ataque personal, que mi dolor no valía nada ante el daño que podía inferir a nuestra causa si abría polémica... ¡que más quisieran ellos!" 35 .

El dolor que acaba de citarse no aparece nítidamente relacionado con el exilio, sino con las rencillas intestinas que debilitaron la República y deshilachaban al Partido Socialista. No obstante, la magnitud de las implicaciones emocionales que el destierro tuvo sobre De los Ríos puede medirse a través de algunos cambios significativos en su comportamiento habitual durante los años precedentes. En primer lugar, se vio obligado a recuperar la actividad docente que la política había hecho pasar a un segundo plano. Fernando de los Ríos no era un político común. Formado en la Institución Libre de Enseñanza, completó sus estudios universitarios en Alemania y consiguió pronto su cátedra universitaria (de Derecho Político, en Granada, en 1911). Aunque su actividad política comenzó pronto, en 1919, nunca abandonó del todo su dedicación a la Universidad. De Granada pasó a la Universidad de Madrid en 1930 donde fue nombrado catedrático de Estudios Superiores de Ciencia Política y de Derecho Político y donde fue rector, en los primeros meses de la guerra. En 1939 comenzó a dar clases en la New School for Social Research de Nueva York, que empezó a ser conocida como 'University in Exile', al haberse ideado para dar cabida a un buen número de exiliados intelectuales de los años treinta y cuarenta ${ }^{36}$, alemanes, básicamente, que habían huido de las persecuciones nazis. En esta dedicación recuperada, la fuente de sufrimiento de Fernando de los Ríos fue siempre el exceso de trabajo: "Perdonadme si os escribo tan poco pero estoy tan agobiado con la preparación del curso que cuando termino la tarea del día, luego he de estudiar durante unas horas intensamente el inglés, leer y tomar notas y escribir un sumario de las conferencias

\footnotetext{
34 ZAPATERO, Virgilio, Fernando de los Ríos: una biografía intelectual, Valencia, Pretextos, 1999 y RUIZ-MANJÓN, Octavio, Fernando de los Ríos: un intelectual en el PSOE, Madrid, Síntesis, 2007.

35 PRIETO, Indalecio y DE LOS RÍOS, Fernando, Epistolario, 1924-1948..., p. 34.

36 KROHN, Klaus-Dieter, Intellectuals in Exile. Refugee Scholars and the New School for Social Research, Boston, University of Massachusetts Press, 1993.
} 
que he de dar, $i 45$ ! de dos horas cada una, quedo sin ánimo de otra cosa que charlar un rato con la familia o... ir al cine. ¡Pero me acuerdo tanto de vosotros! ¡Os echo tanto de menos!" 37 , le escribió a su hermano Pepe. Presentes siempre estuvieron también las preocupaciones económicas: "Resultado material de mi viaje, muy modesto, pero al fin una pequeña ayuda que nos es muy necesaria. Ya sabréis que hemos tomado otro apartamento en la misma casa, un piso más bajo y con dos cuartos menos; pagaremos cuarenta dólares menos al mes, tengo que ver cómo enjugamos el déficit mensual, porque no podíamos resistir ya aquel gasto" 38 .

Los problemas económicos abrumaron a Fernando de los Ríos durante todo su exilio $^{39}$. Sin embargo, donde mejor se rastrean las repercusiones emocionales de su exilio es en su alejamiento de la política. El hombre que, en mayo de 1937 escribió a Ramón Lamoneda ${ }^{40}$ : “... estoy al servicio de la revolución y de la guerra, para todo, absolutamente todo, y lo mismo me da ir de Comisario a la Alpujarra que servir aquí o en Tokio" ${ }^{41}$; el mismo que, en abril de 1939, le escribió a Prieto: "Me doy cuenta muy bien, Indalecio, de sus justificados temores dado el ambiente que ha exacerbado la derrota, pero crea usted que en este respecto no hay motivos para ello y tenemos tiempo sobrado de ponerlo todo en su punto" ${ }^{42}$... es el hombre que en abril de 1940 decidió apartarse de la política activa y que en 1942, en contestación a una carta de Ginés Ganga, dijo: “...soy pues, un hombre que vive al margen de la polémica de los partidos; no me considero ya afiliado a ninguno de ellos. Continúo pensando y sintiendo en socialista al modo como he sentido siempre al socialismo, esto es, con un sentido humanista que en nada se asemeja al marxismo" ${ }^{43}$. La desconexión política que queda descrita en las citas precedentes es, con toda lógica, uno de los primeros pasos en los procesos de reconstrucción emocional que tienen que ver con episodios intensos de sufrimiento emocional de raíz política. El rechazo de lo político es algo así como el acto reflejo que nos lleva a apartar la mano de la llama. También en Salinas encontramos esta pulsión, aunque, en su caso, en clave poética y comprensiva: "Yo, por ejemplo, siento en mí la enorme transformación espiritual que la guerra ha traído a mi ser. Y si escribo más teatro (no veo eso en poesía lírica) lo expresaré, pero sin referirme para nada al hecho mismo de la guerra. Por eso, de las poesías de Alberti, me gusta más lo dedicado al perro porque es lo menos de propaganda" ${ }^{44}$.

Se cierran las compuertas a los temas de los que procede el dolor y, en el aislamiento, se halla refugio. En este sentido, la idea de 'refugio emocional' ${ }^{45}$ no puede ser más pertinente, pues hace referencia a aquellos lugares o pensamientos en los que

37 MUÑOZ ROJAS, Ritama, Poco a poco os hablaré de todo. Historia del exilio en Nueva York de la familia De los Ríos, Giner, Urruti. Cartas, 1936-1953, Madrid, Residencia de Estudiantes, 2009, pp. 70-72.

38 MUÑOZ-ROJAS, Ritama, Poco a poco os hablaré de todo..., pp. 98-99 o 105.

39 MUÑOZ-ROJAS, Ritama, Poco a poco os hablaré de todo..., pp. 180-181.

40 Secretario General del Partido Socialista entre 1936 y 1944.

41 PELÁEZ, Manuel J. y SERRANO ALCAIDE, Concepción, Epistolario selectivo de Fernando de los Rios Urruti, II, Barcelona, 1995, p. 122.

42 PRIETO, Indalecio y DE LOS RÍOS, Fernando, Epistolario, 1924-1948..., pp. 29-31.

43 PELÁEZ, Manuel J. y SERRANO ALCAIDE, Concepción, Epistolario selectivo de Fernando de los Ríos..., p. 123.

44 SALINAS, Pedro, Obras Completas III..., p. 601.

45 REDDY, William, The Navigation of Feeling... 
un individuo que sufre encuentra alivio. La construcción o el hallazgo de 'refugios emocionales' es un elemento fundamental en todo proceso exílico pues, en cierto modo, determina su marcha. Si el exiliado tarda en encontrar la manera o el lugar en el que 'descansar' del esfuerzo emocional que le supone seguir con su vida en unas coordenadas que no había previsto ni deseado, el sufrimiento se hace más intenso, más duradero, y puede llegar a impedir la supervivencia. No es el caso de nuestros dos protagonistas, que además de en su desconexión política, encontraron refugio en el trabajo académico e intelectual. La tarea que tanta desazón provocaba a De los Ríos le sirvió también como válvula de escape. En diciembre de 1939, detallaba a su hermano Pepe: "Como veis, no tengo más que motivos de satisfacción (...) ¡Bastante he conseguido comparado con tantos y tantos compañeros de mérito como se hallan aún sin seguridad alguna!”46. Un año después, aún decía: “...pero aún así, somos privilegiados y no sólo no me quejo, sino que me siento ahora con más aliento que el pasado año. Me van a reeditar dos obras en Buenos Aires y publicarán otras dos nuevas; yo me encuentro bien y además muy animado porque el curso de California resultó un éxito tal, que al final no se cabía en clase" ${ }^{47}$.

En la correspondencia de Salinas es todavía más apreciable esta valoración del trabajo como escapatoria. La pacífica vida de Wellesley había apaciguado sus turbados ánimos. "Hay que reconocer, Marg, que he ganado mucho en paciencia y en adaptación, porque tomo todo esto con buena cara, creo que me acostumbraré y estoy contento. Pero ¿habría podido hacerlo antes? No lo sé. Tengo en cambio un ambiente de calma y tranquilidad perfecto, un paisaje sereno y hermoso, y una soledad que tampoco hubiera soportado antes y que hoy disfruto" 48 . Cuando ya llevaba un tiempo instalado, podía seguir sosteniendo lo mismo: "Estoy a gusto, me agrada re-educarme. Porque tengo para más tiempo, y no prisa. Sólo me faltáis vosotros" ${ }^{49}$.

La sensación de fortuna que Fernando de los Ríos detallaba en las cartas a su hermano también es apreciable, y con más intensidad, en los escritos personales de Salinas. El profesor y poeta no valora sólo la suerte de haber salvado la vida ("No es exageración, Marg pero creo que de haber estado yo en Madrid, dado mi puesto, no escaparía vivo. Unos u otros, antes o después me señalarían como enemigo y caería. ¡Marg, qué suerte hemos tenido!" ${ }^{50}$ ), sino también la posibilidad de seguir desarrollando su proyecto: "Creo, y no sé si me hago ilusiones, que aquí me abriría paso: como ves ya me lo he abierto, en parte, para otro año" ${ }^{51}$. Hay, sobre todo, una mezcla de tristeza y alivio al ver la situación en la que quedan muchos otros: "¡Parece mentira, todo esto! Viéndolo, así, a distancia no se cree. ¿Será verdad que tenemos la patria deshecha, la vida en suspenso, todo en el aire? ¿Qué hacer? (...) ¿Qué van a hacer nuestros amigos, cuando triunfen los fascistas y se les plantee el dilema de someterse o marcharse (si los dejan)? ${ }^{52}$.

\footnotetext{
46 MUÑOZ-ROJAS, Ritama, Poco a poco os hablaré de todo..., pp. 73-75.

47 MUÑOZ-ROJAS, Ritama, Poco a poco os hablaré de todo..., pp. 97-99.

48 SALINAS, Pedro, Obras Completas III..., pp. 516-517.

49 SALINAS, Pedro, Obras Completas III..., p. 541.

50 SALINAS, Pedro, Obras Completas III..., p. 532.

51 SALINAS, Pedro, Obras Completas III..., p. 564.

52 SALINAS, Pedro, Obras Completas III..., p. 539.
} 
Hasta ahora dolor, tristeza, angustia, alivio y hasta cierta felicidad son las emociones que los exiliados de forma más evidente han manifestado. En ese catálogo, no puede faltar la incertidumbre, porque las dudas, las preguntas que nadie salvo uno mismo podía responder, no dejaron de acompañar a los exiliados ni siquiera cuando sus vidas estaban encauzadas. Se ve de nuevo en Salinas, que se plantea mil cuestiones cuando la oferta de una ampliación de contrato le habla elocuentemente de su situación, y que acierta a expresar el núcleo de todo el conflicto emocional que provoca el exilio: "Viviremos aquí bien, lo espero, pero siempre en el fondo de mí habrá, creo, una nostalgia por algo indefinible: la densidad, la antigüedad, de lo humano (...). No creas que estoy desanimado, no. Aún me quedan cosas que ver aquí. Muchas. No me vengo aquí contra mi voluntad. Pero no con toda mi voluntad"53.

\section{El exiliado y sus comunidades emocionales}

El concepto de 'comunidades emocionales' es uno de los más importantes en el desarrollo teórico de la historia de las emociones, por su potencia para imaginar los diferentes ámbitos en los que se mueve un individuo y los mecanismos mediante los cuales adapta su emocionalidad a los mismos. También puede ser uno de los conceptos más importantes en el estudio del exilio: una exploración de las comunidades emocionales a las que se adscribieron los exiliados durante un momento u otro de su experiencia no nos hablará sólo de su capacidad adaptativa, sus refugios, sus estrategias de identificación...; nos hablará también de la amplitud del catálogo emocional que experimentaron. Una comunidad emocional, según Barbara Rosenwein se caracteriza por ser un grupo humano con un sistema de sentimientos y con un código compartido: qué conciben como favorable o amenazante, qué evaluación hacen de las emociones de los otros, cómo son sus lazos afectivos, qué modos de expresión emocional esperan, cultivan, toleran y deploran ${ }^{54}$.

A través de sus cartas los exiliados mantuvieron su vía de comunicación abierta con varias comunidades emocionales a la vez y formando parte de ellas a un mismo tiempo: la familia (si es que alguno de sus miembros no había viajado con él); los compañeros de trabajo (académicos con los que compartieron actividad en el país de origen y que allí se quedaron); otros compañeros de trabajo, conocidos antes, y con los que coincidían (geográfica o experiencialmente) en el exilio; exiliados de otras nacionalidades que en huida de regímenes políticos recalaron en destinos exílicos similares, los correligionarios de filas políticas... Entendemos que estos círculos concéntricos se convierten en la vida del exilio en sus comunidades emocionales porque, insertos en ellas, el exiliado hacía uso de un código expresivo y lingüístico referido a su experiencia, que, sentía, era entendido por todos.

\footnotetext{
53 SALINAS, Pedro, Obras Completas III..., pp. 629-630.

54 ROSENWEIN, Barbara H., Emotional Communities in the Early Middle Ages...
} 


\section{La familia}

Entre septiembre de 1936 y octubre de 1937, el contacto epistolar entre Pedro Salinas y su mujer fue muy intenso. Margarita Bonmatí, que se encontraba en Argelia con los hijos de la pareja, se convirtió en la receptora de cartas emocionadas y útiles para la reconstrucción emocional del poeta durante su exilio. La riqueza de detalles que sobre su vida y sus pensamientos incluyó en sus misivas nos habla bien a las claras del cariz incluso terapéutico que él tenía volcarse en las cartas pero también, y sobre todo, del descanso, de la libertad de pensamiento y expresión que halló en una comunidad emocional de su matrimonio. Una libertad y una comodidad que contrasta con la desubicación que sentía, solo en un país que no le entusiasmaba e inserto en un día a día esforzado, en el que la barrera idiomática no fue un obstáculo cualquiera: "Hoy ha habido un té en mi honor en la casa donde vivo. Todo el mundo muy amable, pero yo, de pie y hablando inglés, lo he pasado bastante aburrido. ¿Qué terrible esto del idioma! (...) Yo me defiendo, hablo algo, entiendo si me hablan a mí, pero cuando la conversación es general apenas entiendo nada" ${ }^{55}$. El elemento esencial de la comunidad emocional Salinas-Bonmatí, en cualquier caso, era ese 'nosotros' que aparece aquí y allá en los escritos del poeta, ese 'nosotros' que era lo único seguro, tanto del pasado como hacia el futuro: "¿Pero verdad que no, Marg, verdad que hicimos bien en marcharnos? No se debe desafiar a la locura, ni a la ferocidad. Eso, no. Tengo pena por ellos, sí, pero tirar la vida a los locos, a la fiera, es inútil. La guardo para ti, para nosotros" "56; "Pero no creas, Marg, que haré lo que me guste, por simpático o antipático al régimen. Lo que hago será pensando en nosotros todos, en lo que sea mejor para todos" 57 .

Y ese nosotros podría concretarse cuando se cumpliera una de las principales expectativas de Salinas una vez se supo exiliado: que su familia se instalara con él en EEUU. No obstante, tenía reservas ante la perspectiva vital de una vida larga allí. Sabía que las condiciones materiales de la familia mejorarían y esa era su prioridad, pero "si vivimos en América, como es lo más probable, siempre se interpondrá como una sombra la idea de que lo hago no por elección libre sino por fuerza de las cosas. ¡Qué terribles palabras, circunstancias, condiciones!" 58 . E iba más allá seguramente por miedo y por responsabilidad ante una decisión de la que dependería la suerte de ese 'nosotros': "Te voy a decir la verdad, ahora mis opiniones no influyen ya en mis actos, y que nuestra decisión de venirnos aquí está tomada. América me ha defraudado y desilusionado, mucho. ¿Por qué? Para mí, un país me interesa solo como un modo de concebir la vida, de vivir. Francia es una visión de la vida, España otra, y así todos los países grandes. O que lo fueron. Y el modo americano no me atrae, hasta ahora. No es país que te indigne ni repela, no. Pero no entusiasma. Ese es mi estado: falta de entusiasmo ${ }^{59}$.

\footnotetext{
55 SALINAS, Pedro, Obras Completas III..., p. 530.

56 SALINAS, Pedro, Obras Completas III..., p. 515.

57 SALINAS, Pedro, Obras Completas III..., p. 547.

58 SALINAS, Pedro, Obras Completas III..., p. 621.

59 SALINAS, Pedro, Obras Completas III..., pp. 629-630.
} 
Salinas había podido hacerse una idea de lo que podía ser la vida de una familia entera en el exilio y lo había compartido con Margarita. Lo había visto al visitar a otro exiliado, austriaco, su colega hispanista Leo Spitzer, con quien coincidió estando ambos instalados en EEUU. Aunque ya se conocían, su primer encuentro americano dejó esta impresión emocional en Salinas: "Esta noche he cenado en casa de Spitzer, el profesor alemán que me invitó a Colonia hace años. Esta aquí desde octubre casi como yo, ha sido un verdadero diálogo de emigrados. Él no podrá volver a Alemania, porque es judío y anti-nazi. Ha estado en Turquía tres años. Me ha hecho impresión, la visita. Son él, la mujer y un chico de unos 15 años. Viven modestamente, sin criada. La mujer no habla más que alemán. Hemos estado echando de menos Europa y lo europeo. Su conversación no ha sido muy animadora (...) pero he vuelto a tener la sensación del emigrado. ¡Palabra romántica, palabra nacida hace unos 150 años y que ahora se pone de moda otra vez! Yo la leí siempre con una sonrisa un poco irónica, como si fuese una palabra literaria. Y esta noche, hablando con Spitzer me vi, como en un espejo, en ella". ${ }^{60}$

La familia fue también unas de las comunidades emocionales más importantes en el exilio de Fernando de los Ríos. En primer lugar, la familia que vivió junto a él en Nueva York: su esposa, su hija, su madre y su suegra. La madre de De los Ríos, llamada cariñosamente la Bisa, fue el principal elemento aglutinador de un grupo familiar cuyos miembros hicieron todo lo posible por apoyarse entre sí y en el que hubo un esfuerzo consciente por ser un bloque unido y alcanzar cierta cotidianidad en sus vidas: "Nada de hundirse ni entristecerse; mirad hacia adelante con brío y fe; siempre, siempre encontráreis nuestros brazos y nuestro enorme cariño" ${ }^{61}$. La sensación de normalidad y saber que las cosas iban relativamente bien ayudaba mucho a pasar el trago: "Además, veros a todos vosotros en franquía y a mamá y tía Laura tranquilas por el porvenir, o mejor dicho, por el presente, es algo de valor inconmensurable" 62 . Todos los miembros de la familia, a uno y otro lado del Atlántico, dieron enorme importancia a la comunicación por carta como manera de seguir formando los unos parte de las vidas de los otros y para que la situación fuese menos dolorosa. Para una comunidad emocional, saber, aunque a veces se trate de noticias tristes, siempre es mejor que la incertidumbre. Y así, los De los Ríos, una familia rota y deslavazada por el exilio, reconstruyó sus lazos contándose proyectos ${ }^{63}$, enviándose ayuda ${ }^{64}$, compartiendo ilusiones ${ }^{65}$, informándose de achaques y enfermedades ${ }^{66}$; intercambiando fotografías ${ }^{67} \ldots$ en fin, compartiendo la vida aunque las cartas se retrasaran o se perdieran: "Cada uno por su distinto modo de ser llenáis una necesidad de mi espíritu; por eso os pido que siempre que podáis escribáis larga y minuciosamente, pues go-

60 SALINAS, Pedro, Obras Completas III..., p. 614.

61 MUÑOZ-ROJAS, Ritama, Poco a poco os hablaré de todo..., pp. 100-101.

62 MUÑOZ-ROJAS, Ritama, Poco a poco os hablaré de todo..., pp. 73-75.

63 MUÑOZ-ROJAS, Ritama, Poco a poco os hablaré de todo..., pp. 105-106.

64 MUÑOZ-ROJAS, Ritama, Poco a poco os hablaré de todo..., pp. 125-126, 211-212; 274-278.

65 MUÑOZ-ROJAS, Ritama, Poco a poco os hablaré de todo..., pp. 113. 349.

66 MUÑOZ-ROJAS, Ritama, Poco a poco os hablaré de todo..., pp. 117-120, 162-163, 170-171, 278-281,

67 MUÑOZ-ROJAS, Ritama, Poco a poco os hablaré de todo..., pp. 117-120. 
zamos todos enormemente con vuestras cartas. (...) Da detalles siempre de tu vivir. ¡Nos hacéis un grandísimo bien!"68.

\section{Los círculos profesional e intelectual}

La integración en un círculo laboral y el desempeño de una actividad profesional son elementos clave en cualquier proceso exílico. De ellos se deriva la integración o no del exiliado en una comunidad emocional que, en el caso de los protagonistas de este trabajo, estaba unida por algo más que por la realización de una misma tarea y era consciente de las circunstancias de sus miembros. Los casos de Salinas, Castro y De los Ríos son en apariencia diferentes pero en el fondo, bastante similares. Ya nos hemos referido a la sensación de aislamiento y soledad que Salinas experimentó en el ámbito laboral, pero la fotografía no estaría del todo completa si ignorásemos el buen trato que quienes supervisaban su trabajo le dispensaron: "Era para ofrecerme para el año que viene mi puesto aquí si quiero seguir. Ha estado muy amable conmigo, me dice que están muy contentos de mi trabajo y de tener en el Departamento a una persona como yo, y me propone que me guarde el año que viene" 69 .

El caso de Fernando de los Ríos es más claro, ya que comenzó a dar clases en la New School for Social Research donde se integró plenamente y donde consiguió tener una situación estable, bien es verdad que a costa de un intenso trabajo y de viajes para dar conferencias o cursos con que complementar ingresos ${ }^{70}$. El grado de integración, y también la intensidad del apoyo que la comunidad emocional brindaba a sus miembros, pudo comprobarse cuando la salud de Fernando de los Ríos comenzó a deteriorarse, así escribía su esposa: "Aunque ando de cabeza hoy no quiero que vaya ésta sin deciros que Fernando va a dejar de dar clase en la New School. (...) El presidente le llamó y le dijo que habían estado tratando su situación los compañeros más amigos y él y habían decidido que interrumpiese sus clases (...) Y que tenían el dinero para que se dedicase exclusivamente a sus libros (...). ¡Qué bien se portan siempre!"71.

Con Américo Castro, colega en Madrid y también en el exilio, Pedro Salinas mantuvo asidua correspondencia desde el mismo julio de 1936 hasta su fallecimiento en 1951. El compromiso de Castro con la República se evidenció tan pronto como esta fue proclamada y fue nombrado embajador en Berlín. Comenzada la guerra se desplazó a San Sebastián donde estaba su familia. Fue nombrado entonces cónsul de la República en Hendaya y desde allí pudo organizar la salida de buena parte del cuerpo diplomático, él mismo incluido. Estuvo en Argentina (allí estaba en noviembre de 1936 invitado por la Asociación Cultural) y en 1937 llegó a EEUU. Allí fue primero profesor en la Universidad de Wisconsin (de 1937 a 1939) luego en Texas y en Princeton ${ }^{72}$.

\footnotetext{
68 MUÑOZ-ROJAS, Ritama, Poco a poco os hablaré de todo..., pp. 70-72.

69 SALINAS, Pedro, Obras Completas III..., p. 564.

70 MUÑOZ-ROJAS, Ritama, Poco a poco os hablaré de todo..., pp. 73-75, 105-106, 240-242.

71 MUÑOZ-ROJAS, Ritama, Poco a poco os hablaré de todo..., p. 329.

72 MORALES MARTÍN, Juan Jesús (ed.), Américo Castro, 1885-1972, Madrid, AECI, 2012.
} 
Las cartas que Castro y Salinas cruzaron sirven como muestra de la comunidad emocional que el exilio español en los EEUU iba construyendo. Una comunidad reconstruida, con cimientos previos en el CEH - donde también Castro había trabajadoexigida y necesaria para el propio Castro, los "españoles de esta diáspora -plantearía ya en el otoño de 1936- tenemos que estar en relación"73. En la comunidad emocional/ profesional se compartieron, desde muy pronto, las dificultades administrativas del desplazamiento. En momentos tan complicados para moverse por el mundo, eran frecuentes las referencias y consejos sobre las fórmulas legales exigidas para la instalación en EEUU. Ante las incomodidades que este proceso estaba generando en Castro, Salinas alentaba enseguida: "Respecto a sus dificultades de red tape americana le diré que yo entré como non quota, con pasaporte expedido por el cónsul americano en Biarritz, y la policía, al llegar me dio la tarjeta autorizándome a residencia indefinida. Creo que se la dan a todo extranjero, profesor, que presenta su contrato. Deseo vivamente que se le arregle pronto tan fastidioso asunto, no puede ser otra cosa que cuestión de tiempo y latas".

La posibilidad que ambos gozaban de tener un trabajo y una vida tranquila les ayudaba a no sufrir en directo la agonía española y a salvar en lo posible lo bueno que allí se hacía. "¿Para qué hablar de la agonía hispánica? -se preguntaba Salinas- no dejo de pensar ni un momento en los amigos de allí, como Dámaso [Alonso]. ¿Qué va a ser de ellos, entre el recelo del Gobierno y barbarie de Franco? Los meses venideros se ofrecen horribles a la imaginación. Pero me conformo más y más en mi idea de que los españoles que andamos por aquí debemos pensar en salvar lo que se pueda y en acercarnos para esa obra". Salvar y acercarse son verbos que se repiten en las primeras comunicaciones en el exilio de Salinas hacia Castro. Hacer la vida, conectar con los amigos y colegas de profesión es lo que les permitía confiar en que algo podía salvarse ${ }^{74 .}$

Pudieron celebrar ambos los buenos puestos académicos que consiguieron: a comienzos de 1940 Castro fue nombrado catedrático en Princeton y Salinas en Johns Hopkins University, en Baltimore. "Vacilé mucho antes de decidirme a dejar Wellesley, sede de calma, silencio y tranquilidad, que tanto bien me ha hecho. (...) Pero entre mis razones de alegrarme del traslado figura, y muy en primer término, la de estar cerca de Princeton, poder ver a ustedes con alguna frecuencia y sentir que (...) cada uno dentro de nuestra capacidad, (podemos) elevar un poco el tipo de los estudios hispánicos en América". Y más buenas noticias seguían llegando de la producción intelectual que, de nuevo, había cogido ritmo. Podían celebrar, por ejemplo, que Castro estuviera trabajando en su volumen sobre la historia de la literatura española. "Sería estupendo -reconocía Salinas- que la mejor Historia de la Literatura Española se la hiciera a España un emigrado, mientras aquella ralea se entrega a la retórica menendezpelayesca de segunda mano, revolcándose en el neoacademicismo de Ors" ${ }^{\text {". }}$. La vida profesional poco a poco se encauzaba.

73 CASTRO, Américo. MS Span 100. Salinas, Pedro, Papers. Houghton Library, Harvard College Library.

74 SALINAS, Pedro, Obras Completas III..., pp. 668-669.

75 SALINAS, Pedro, Obras Completas III..., pp. 805-806. 
A la constante preocupación por la suerte de los colegas que no estaban con ellos se unía la celebración, íntima pero también compartida en la comunidad emocional, porque las cosas marchaban razonablemente bien. Los exiliados conocieron también el éxito cifrado en un bienestar, que, por compartido, resultaba estimulante y menos culpable. "Como ustedes saben -contaba Salinas a Castro en 1942- compramos una casita; tras el inmueble vinieron los muebles, y a la cola de los muebles, las cuentas, los famosos plazos. En tiempo de normalidad hubiéramos podido afrontar la situación tal cual. Pero con el terrible horizonte fiscal, en marea ilimitadamente creciente, estoy aterrorizando. Y no gasto un céntimo, fuera de los terribles plazos inexorables (...) Y el caso es que es indecente quejarse lo sé. Y que me doy por contentísimo de levantarme día tras día y tener la naranja en la mesa".

El exilio les estaba llevando también a darse cuenta de que en el universo académico norteamericano no sólo habían recalado ellos, los españoles "apurados, náufragos, agonizantes y desvalidos". Castro advierte de la presencia de cantidad de matemáticos, todos locos según él, de origen alemán, que solían tener una mejor posición y salario que los españoles: "Los ángeles estos cobran \$15000 al año. Luego otro grupo, "lógico", me aclaró que los matemáticos se chalan porque tiene que demostrar todas las quimeras que se les ocurren, y al no poder a veces, se les liquida el magín". Pero pese a esta locura, encontraba más en común con estos exiliados que con otros colegas lejanos, "yo prefiero este ambiente de insensatez admirable a la prosa espantosa y sin estilo, que ya conoce". Las identidades mezcladas en la transnacionalidad del exilio ofrecían también una posibilidad de crear comunidad emocional.

El exilio español había coincidido con otros, el alemán sobre todo pero no sólo. Y en ese contexto de diáspora internacional instalada en EEUU, muchas iniciativas habían visto la luz. La más conocida y exitosa, sin duda, la neoyorquina New School for Social Research que había permitido también a españoles como De los Ríos o Alfredo Mendizábal integrarse en esa otra también comunidad de exiliados. En 1942 Castro tuvo constancia de que también los franceses estaban intentado crear una universidad en el exilio (l'École Libre d'Hautes Études) también en New York. Por la conexión que siempre tanto Castro como Salinas habían tenido con Francia, ambos parece que se comprometieron a participar en ese proyecto y que también lo hizo Jorge Guillén. Fue Castro quien entabló las negociaciones y, en un principio, estaba claro que, de participar, lo harían en castellano. No obstante, el criterio de los organizadores cambió y entendieron que toda docencia habría de dictarse en francés. Lo que se inició, según Castro, como una humilde petición de ayuda "en un momento angustioso para Francia", al cabo de un año y debido al éxito obtenido acababa siendo una especie de atalaya propagandística a favor de la civilización francesa que conducía a tratar a todo el mundo como "tunecinos o vietnamitas". Esta tensión con los organizadores hizo que Castro renunciara a toda colaboración, a toda posibilidad de añadirse a esa otra comunidad de exiliados.

El contacto entre exiliados, la constitución entre ellos de una comunidad emocional (fueron frecuentes las conversaciones entre Salinas y Spitzer, como avanzamos ya) a través de las cartas pero también de visitas mutuas por razón familiar o profesional se convirtió entonces, como Salinas reconoció, en la manera de "charlar, de 
animarnos mutuamente, de hacernos ilusiones juntos, de probarse proyectos en la opinión del amigo, en suma, de ayudarse a vivir" ${ }^{\prime \prime 6}$.

Cuando ya habían pasado casi diez años de su exilio, cuando ya tanto Salinas como Castro, estaban acoplados a sus tareas fuera de España, a Castro, como al principio, le pesaba la soledad de enfrentarse al trabajo intelectual sin poder tener más cerca el consejo y la crítica de Salinas. En enero de 1946 afirmaba: "no sé y siento estar tan solo". Y solo dos años después redondeaba mejor la emoción de la soledad: "No está uno solo si está bien en sí".

El pesar por la suerte de los colegas, dentro y fuera de España, no se alivió en absoluto con el correr del tiempo. En 1948, Castro expresaba su enorme preocupación por la suerte de la familia de los Ríos en el momento en que la salud de Fernando había empeorado. "Estuve allí hasta tarde el sábado, pero no cabe hacer cielos. Me dieron pena. Liquidación por derribo". Con esta visión concluía, una vez más, cuán afortunados él y Salinas seguían siendo: "Tenemos cosas, como no. Pero estamos en pie, y con el arma (línea encendida, prosa terrestre) al brazo" "77.

Pero esa paz, no hacía que nuestros protagonistas fueran ajenos de lo que a otros exiliados sucedía, aquellos que llegaron antes, de los que a Castro le había llamado la atención su excentricidad y que, como también sucedió con algún español, no escaparon de la tentación de acabar con todo, de suicidarse. "Estuvimos en Cambridge - cuenta Salinas a Castro en abril de 1950 en una de sus últimas cartas ya. (...) Lo triste fue, al día siguiente de llegar el suicidio de Mathlessen, uno de los jóvenes de más promesa en Estados Unidos. Nuevo número en la lista de Ernest Toller, Stefan Zweig, Klaus Mann. Los desesperados del mundo actual"178.

\section{Los que se quedaron y los que se fueron}

"Cada vez temo más por los que allí están, por los amigos”79, escribía Salinas. Y esta preocupación constante por compañeros que quedaron atrás es un elemento común en la correspondencia en nuestros tres protagonistas. En la angustia con que esperaban y recibían las noticias y en la energía que pusieron en tratar de ayudar a todos los que pudieron hay la huella de una comunidad emocional perdida y que pretende siempre reconstruirse. Los que se quedaron fueron muchos, pero también fueron muchos los que salieron de España y se convirtieron en exiliados. La primera sensación de quienes luchaban por reconstruir sus vidas en otros países fue de fortuna, tanto para los dos profesores como para el académico y político, pero también se ofrecieron, como lo hizo de los Ríos, a ayudar a los refugiados: “....ayudar moral y materialmente cuanto os sea posible a todo español decente y desventurado, porque sólo así cumplimos con nuestro deber de hombre y de español en estas horas terribles" ${ }^{\prime 80}$.

76 SALINAS, Pedro, Obras Completas III..., p. 1010.

77 SALINAS, Pedro, Obras Completas III..., p. 1270.

78 SALINAS, Pedro, Obras Completas III..., p. 1342.

79 SALINAS, Pedro, Obras Completas III..., p. 512.

80 MUÑOZ-ROJAS, Ritama, Poco a poco os hablaré de todo..., p. 77-79. 
El dolor y la angustia por los amigos que estaban en España y la desesperación por no poder hacer nada por ellos o, peor, que estos se hubieran resignado era algo que torturaba a Salinas y a Castro. Sacarlos de España, especialmente a Dámaso Alonso, se había convertido para Salinas en un tormento. Cuando Castro dejó su puesto en Wisconsin, en abril de 1939, Salinas retoma la idea de que Dámaso Alonso pudiera instalarse allí: “ ¡Cuánto nos importa, pues por él, primero, y luego por la causa general, sacar a Dámaso de allí! ¿Sería posible? (...) Estaría muy bien en ese puesto. ¿Qué le parece a usted? Si coincide conmigo y quiere usted actuar rápidamente, él, yo, todos, se lo agradeceremos infinito" ${ }^{81}$. Les sorprendía sobremanera la opción de Alonso por lo que se ha acabado llamando 'exilio' interior y que Salinas tan bien describe como un "estado transitorio de pacto con las cosas" y les desesperaba pensar "que va a trabajar entre esa gentuza." Para Castro, tener a Alonso en América, le permitía soñar con crear un potente grupo de hispanistas en EEUU, una comunidad emocional que acabaría siéndolo profesional de nuevo, otra vez el CEH pero ahora al otro lado del Atlántico. El sueño pudo concretarse, por ejemplo, una vez que Salinas dejó su puesto en Wellesley, y fue Jorge Guillén quien lo sustituyó ${ }^{82}$.

Las visiones estáticas del exilio se han cebado especialmente con las relaciones que los exiliados establecieron en los países de destino. Ha parecido que cada comunidad de exiliados se movía entre la amistad y la enemistad, sin términos medios ni virajes concebibles. Se trata de una visión muy limitada puesto que cada exiliado vivió su relación con otros exiliados de forma particular y cambiante en los distintos momentos de su vida. En el caso de Salinas, la emoción predominante fue la amargura. Fue muy pronto consciente de que la política lo envenenaba todo ("Ya empieza uno a padecer lo que va a ser la cosecha terrible de la guerra: la división de todos, de todo, en dos bandos que no se perdonarán" ${ }^{83}$ ), recibió y formuló críticas ("De lo que me quejo es de que se tome a todo el que está fuera de España como un desafectado o enemigo. Es decir una división arbitraria y caprichosa más" ${ }^{84}$ ) y nunca se sintió cómodo con la que calibró como actitud típica del exiliado español: "Voy creyendo que es mejor no ver a españoles. (...) Me voy convenciendo de que la posición peor del español en el extranjero es la de que está aquí con su cuerpo (...) pero pensando en allí, en lo de allí. Todos los españoles que llevan mucho en el extranjero, Onís, Madariaga, Pijoan, Viñas, se parecen en lo mismo: en quejarse de los de allí, en envidiarlos" ${ }^{85}$. Se apoderó de él, en suma, una visión muy pesimista: “¿Qué va a quedar de España, se pregunta uno. ¡Qué horizonte! Ruinas, muertos, fieras y sometidos y humillados esclavos" $" 86$.

También hubo amargura en las reflexiones de Fernando de los Ríos sobre determinados grupos lanzados al exilio por la derrota de la República. Era una amargura más concreta que la de Salinas, pues se derivaba directamente de las cuitas intestinas

81 SALINAS, Pedro, Obras Completas III..., pp. 727-728.

82 CASTRO, Américo. MS Span 100. SALINAS, Pedro, Papers. Houghton Library, Harvard College Library.

83 SALINAS, Pedro, Obras Completas III..., p. 610.

84 SALINAS, Pedro, Obras Completas III..., p. 606.

85 SALINAS, Pedro, Obras Completas III..., p. 597.

86 SALINAS, Pedro, Obras Completas III..., pp. 599-600. 
que habían carcomido el cuerpo político republicano antes y durante la contienda ${ }^{87}$, y fue unas de las causas que animó a De los Ríos a retirarse de la actividad pública. Durante el tiempo que permaneció alejado de la misma, todos sus comentarios sobre la dedicación política y sobre la actitud de algunos exiliados fueron bastante críti$\cos ^{88}$. Sin embargo, existía en él un compromiso político que, aunque adormecido por el dolor primero del exilio, repuntó cuando la vida estaba de nuevo encauzada y la situación global resultaba esperanzadora. En el regreso de Fernando de los Ríos a la política hubo, se verá más adelante, tanto de superación de una fase como búsqueda de refugio ante otra por venir.

En su experiencia ya de casi ocho años en el exilio americano a Salinas le pesaba también el comportamiento de colegas españoles en el exilio que, a su juicio, habían "traído en el alma, desde Madrid a América, ese cargamento de chismes, minucias y rencores, y más aún el darlos ahora a los cuatro vientos para desprestigio de los españoles emigrados". Y Castro no dejó de corroborar su pensamiento sobre los vicios y pecados de los españoles. "Casi todos los hispanos son saquitos de veneno, podridos de envidia y resentimiento. Siempre fue así, no sólo entre hispanos; pero lo grave ahora es que hemos perdido la almohadilla que amortiguaba las coces. Hay que dormir sobre piedras, y hacerse piel de hipopótamo. Casi la tengo. Mi consuelo es que sé por qué son así las cosas...”.

\section{Reconstrucciones emocionales}

Una reconstrucción emocional, o eso a lo que William Reddy se refiere como una 'navegación emocional' exitosa, consiste en un esfuerzo, a medias consciente y a medias inconsciente, por adaptar algunas metas a una nueva situación vital, con el objeto de evitar, si es posible, el conflicto de metas y el sufrimiento emocional ${ }^{89}$. Un primer ejemplo de esta reconstrucción es la relación con la política que sostuvo en su exilio Fernando de los Ríos. Una relación que introdujo un elemento de atipicidad en su proceso de reconstrucción emocional porque, al alejamiento del primer momento, siguió un nuevo interés y un nuevo compromiso más tarde y que indica que su proceso de reconstrucción emocional no estuvo nunca del todo cerrado. Su reconstrucción emocional, no obstante, no giró solamente en torno a la política y se consumó con éxito en su integración plena en la New School for Social Research y en los círculos sociales a los que tenía acceso por su condición de profesor y exiliado.

En la carta que Fernando de los Ríos escribió a su hermano Pepe en diciembre de 1944, podemos observar el grado mayor quizás de su adaptación a la situación del destierro: "Te escribo el día de mis ¡65! cumpleaños (...) ¡Cuánto deseo de terminar con esta dura época de interinidad! A veces me siento cansado de esta brega en tierra extraña, pero cuando me paro a considerar la diferencia de situación con respecto a los más de los desterrados, me reprocho mis murrias, porque en verdad somos afor-

87 PRIETO, Indalecio y DE LOS RÍOS, Fernando, Epistolario, 1924-1948 ..., pp. $29-31$ o p. 34.

88 PRIETO, Indalecio y DE LOS RÍOS, Fernando, Epistolario, 1924-1948 ..., pp. 39-41, 66-68.

89 REDDY, William, The Navigation of Feeling... 
tunados entre los centenares de miles de compatriotas en el exilio. ¡Y es que algunos días siento la edad, no obstante de estar fuerte y bien!" ${ }^{90}$. Nunca dejó de sentirse un desterrado, un interino en tierra extraña, pero también afortunado por la buena marcha de su carrera profesional y de las vidas de sus seres queridos. Cuando escribió esta carta, ya hacía tiempo que había vuelto a despertarse en él el interés por la política, sobre todo tras el estallido de la Segunda Guerra Mundial. "Aun cuando yo estoy al margen de toda acción política y me limito a ayudar cuanto puedo a los refugiados, este asunto tiene dimensiones tan esencialmente humanas y dramáticas, que no quiero rehuir esfuerzo alguno que pueda servir, siquiera sea, a un intento de solución", le escribió a Indalecio Prieto en enero de 1940, sobre la posibilidad de que la Iglesia católica mediase para mejorar la situación de los refugiados españoles, en el nuevo contexto de guerra europea ${ }^{91}$. Fernando de los Ríos no dejó de estar atento al desarrollo de la guerra y a las repercusiones que ésta podría tener sobre España: “¿podrá Franco evitar la entrada de España del lado de los alemanes? Ésta es la pregunta que me hacen muchos; mi respuesta es que no él sino el pueblo español es quien impedirá que eso ocurra", escribió en noviembre de $1942^{92}$. En diciembre de ese mismo año: "Todo va mucho mejor, pero esta guerra va a legar a la generación que viene una herencia tan cuantiosa de odios y destrucción como no se había conocido; y recobrarse de ambas cosas ¡requerirá tanto tiempo! En fin, ique se acorte el plazo de la lucha es por el momento la sola obsesión!"’93.

Los avances aliados permitían albergar esperanzas respecto a un cambio de la situación en España. En carta a su hermano Pepe, con quien más abiertamente trató estos temas Fernando de los Ríos, escribió: "Finalmente, la guerra va muy bien y, a semejanza de lo que va pasando en los demás países europeos, a la postre se impondrá en España un régimen de libertad y respeto democrático" 94 . Esa ilusión, sumada a la responsabilidad que sentía respecto de España, le llevaron a adherirse a la Junta Española de Liberación: "Sí, comprendo tu impresión al leer lo de mi nombramiento para la Junta Española de Liberación, pero el asunto es sagrado y no hay medio de rehusar. Veremos qué resultado se obtiene", explicó de nuevo a su hermano en diciembre de 1943. Un año más tarde insistía: "Es posible que tenga que ir a México para la reunión de Cortes, ¡veremos!, es un compromiso difícil de rehuir si se piensa en España”. En las cartas a Indalecio Prieto y Diego Martínez Barrio expresó más claramente su compromiso. "Si tienen ustedes interés, puedo enviarles de vez en cuando recortes de importancia sobre el problema español o sobre la política internacional en general $\mathrm{y}$, si los considerasen de trascendencia para el inmediato futuro de España, sobre la enorme revolución técnica que se está operando en la industria de este país" ${ }^{95}$.

Del seguimiento de la actividad política también se apartó Salinas. En su caso, este apartamiento, en su proceso de reconstrucción emocional, tenía que ver con su

\footnotetext{
90 MUÑOZ-ROJAS, Ritama, Poco a poco os hablaré de todo..., pp. 200-201.

91 PRIETO, Indalecio y DE LOS RÍOS, Fernando, Epistolario, 1924-1948..., pp. 60-61, 66-68, 85-86.

92 MUÑOZ-ROJAS, Ritama, Poco a poco os hablaré de todo..., pp. 145-146.

93 MUÑOZ-ROJAS, Ritama, Poco a poco os hablaré de todo..., p. 150.

94 MUÑOZ-ROJAS, Ritama, Poco a poco os hablaré de todo..., p. 179-180.

95 PRIETO, Indalecio y DE LOS RÍOS, Fernando, Epistolario, 1924-1948..., pp. 107-110.
} 
necesidad de no asistir al hecho de que su círculo de amigos españoles con los que tantas experiencias había compartido se acabara rompiendo y enfrentando. "De modo que por una parte yo deseo, naturalmente, que sean derrotados los fascistas cuanto antes, que gane la República. Pero ya veo que esa victoria acarrearía inevitablemente la desgracia de un amigo ${ }^{96}$. La política se había instalado en todo y él mismo no acaba de entender por qué no había sentido la misma tentación: "Sabes, Marg, te confieso que yo al ver tantos y tantos casos no comprendo cómo a mí no me ha arrastrado la misma ola, la de Alberti, la de Pepe, la de Amós, la de Enrique. Ya no me arrastrará, lo sé. (...) Mi ideal es cada día más, de paz, de retiro, de trabajo lento, con vosotros"

La necesaria y personal reconstrucción emocional tras la decisión misma de emigrar llevaba aparejado sobreponerse a las críticas, reservas y dudas que esa decisión había podido provocar y a situarla de nuevo en el mismo contexto de enfrentamiento político del que tanto Salinas huía: "Parece ser que mi actitud al venirme a América es bastante discutida, por la gente en España y se interpreta, por los que llamaríamos mis enemigos, como una huida o prueba de falta de adhesión al gobierno. Es decir, que estoy aislado como sospechoso por los unos y por los otros. Y por consiguiente que el día de mañana, aunque gane el gobierno, yo que he estado en conciencia, como tú sabes, más a su lado que al otro, seré mirado con recelo. Naturalmente, yo comprendo que a los que no hemos estado allí, pasando los sufrimientos y angustias (...) no se nos puede considerar lo mismo, y no me quejo de eso ${ }^{98}$.

La reconstrucción pasaba igualmente por asumir y diseñar una nueva relación con el país de origen y con la nacionalidad. Asistir al desastre que se estaba desarrollando en España ofrecía ya la primera prueba y Salinas lo cifra muy bien asegurando que, si pudiera, incluso renunciaría a su condición de ciudadano de un mundo civilizado. "Mucho deseo -auguraba Salinas a Castro- que esté contento con su trabajo en Wisconsin, y eso le ayude en cierto modo a llevar ese peso moral de la expectativa y la angustia por las noticias de España que todos los españoles sufrimos (...) No me indigna, tan solo, el hecho mismo, sino la indiferencia con la que el mundo civilizado contempla esos asesinatos, sin intentar forma alguna de intervención o condena. (...) Siento una desilusión creciente por todo lo que se llama mundo civilizado. Y si fuera posible renunciar, como se renuncia a una nacionalidad, a pertenecer a ella, lo haría" $" 99$.

Asumir el exilio, suponía muchas cosas, como planteaba Castro, por ejemplo, pasaba por entender que ni los españoles de dentro ni los españoles de fuera se estaban ocupando convenientemente de España. "Mientras tanto, todos descuidaban a España, incapaz de darse contenido y de darse forma"; "¿A qué dirección postal se le puede escribir a España? Los insensatos españoles pretenden que les hagan a España desde fuera de ellos mismos. No, amigo Salinas; de lo informe no sale la forma. (...) Mientras España no se decida a existir en la acción (...) el país seguirá siendo una aglomeración, casual y dolorida, unas gentes que yacen pegadas a una tierra, a unas ciudades; la mayor parte de ellos serían dichosos si pudieran marcharse a cualquier

96 SALINAS, Pedro, Obras Completas III..., p. 610.

97 SALINAS, Pedro, Obras Completas III..., pp. 599-600.

98 SALINAS, Pedro, Obras Completas III..., p. 606.

99 SALINAS, Pedro, Obras Completas III..., p. 650. 
parte, huyendo de su inexistencia como cuerpo colectivo". No libraba de las culpas a la emigración tampoco, a los que, como ellos, lo veían todo en la distancia: "El que de la emigración no haya salido ninguna palabra verdadera es signo catastrófico. V. ha dicho alguna vez que España debiera ser entregada a un contratista que se encargara de su vida (...) su aserto es más verdad que nunca. Pobres de aquellas gentes, y pobres nosotros. Seguirán hablando los emigrados del "antifascismo", como si ser antifascista significara algo distinto de formar una liga contra el ácido prúsico".

Parecía que la mejor forma de reconstruirse, pasaba pues, por mantener una relación productiva con la nación dejada, a través de la propia creación intelectual y por adaptarse en la medida de las posibilidades al medio americano. ¿Cómo acometer la primera tarea? Como hemos visto, Castro animó, durante todo su exilio, a que otros colegas españoles se les unieran, siquiera temporalmente, en suelo americano. Que Dámaso Alonso o Lapesa participaran en los cursos de Middelbury College le daba la posibilidad de tener "un trozo de Centro $(\mathrm{CEH})$ virtual". La aspiración parecía permanecer intacta aún en febrero de 1948 de cuando es esta frase de Castro. Verse un buen puñado de profesores y especialistas españoles en los cursos de verano era entendido, también por Castro, como una de las mejores formas de ser nacional, de "ser nacionales de nuestras obras". En la adaptación era necesario, superar, por ejemplo, como se ha visto, el escollo fundamental que agrió los primeros meses de trabajo de Salinas y de De los Ríos en EEUU, el idioma. Y yendo, más lejos, como lo fue Castro, la integración pasaba por la participación política en el país de acogida. En las elecciones de 1944, Castro pudo votar y lo hizo a favor de Roosevelt.

No obstante, y más después del fin de la Segunda Guerra Mundial, la idea del retorno a España no había sido desterrada del todo por más que se viera muy difícil. En 1946 Salinas desde su dorado retiro de San Juan de Puerto Rico reflexionaba ante Castro sobre las dificultades en España: "empezaron los españoles del 98 a plantearse a España problemáticamente, vinieron luego los trabajadores a intentar echar anclas aquí y allá. Pero se me figura que a los cincuenta de aquel desastre menor, ahora en la estela de otro gran desastre mayor de la guerra civil, va a volver a alzarse otra vez esa España problemática, ese neo-98, aún sin fecha, porque no sabemos cuándo será la del retorno. Entretanto, lo único posible, vitalmente, moralmente, es hacer lo que usted hace, pensar, escribir, trabajar profundamente" ${ }^{100}$.

En definitiva, el exilio había supuesto una transformación personal total. Casi a modo catártico, completando el proceso de reconstrucción emocional que el exilio significaba, éste debía haber hecho de los que se marcharon alguien necesariamente mejor y más puro y con posibilidades mayores de aportar algo si finalmente regresaban: "No comprendo cómo un español pueda oír sufrirse su ocio vacío, a no ser que él mismo esté vacío, o lleno de politiquerías baratas. El que vuelva a España con las manos tan sin nada como cuando salió, o cargado de combustible para la nueva hoguera sacrificial, no merece volver. Solo nos justificará lo que llevemos, cada cual según su capacidad y sus medios. Si el destierro es bueno es por lo que tiene de espoleo y de purificador. Por lo menos nosotros hemos tenido la inmensa suerte de haber podido

100 SALINAS, Pedro, Obras Completas III..., p. 1066. 
seguir pensando sin tener que ahormar nuestro pensar y nuestro hacer a modelos de Estado, como aquellos pobres que viven y sufren en España"101.

\section{Conclusiones}

Ni De los Ríos, ni Salinas, ni Castro volvieron a España para quedarse. De los Ríos murió en New York en 1949; Salinas en Boston en 1951 y Castro en un viaje a España para visitar a su hija en 1972, cuando ya vivía en EEUU como profesor jubilado. Recorrida por los tres la cartografía emocional en el exilio, un somero análisis de sus epistolarios ofrece la posibilidad de explorar sus experiencias en ese proceso a la luz de la conceptualización avanzada por la historia de las emociones. En los exiliados se advierte desde el comienzo sufrimiento y esfuerzo emocional, lo que les llevó enseguida a localizar sus espacios para el descanso y el refugio. Una vez que tomaron conciencia de que iban a vivir como exiliados, tocaba detectar y construir las comunidades emocionales con las que entablarían contacto para deplegar y desahogar sus emociones, pero también ubicar sus vidas, sus experiencias comunes y sus expectativas. La familia, el círculo profesional y el contacto y las referencias tanto de los colegas que se habían quedado en España como de otros tantos (españoles o no) que compartían exilo, se detectan con facilidad como esas comunidades emocionales construidas. Dilatado el proceso exílico ya plagado de vaivenes y emociones encontradas, y para vivir y no sólo sobrevivir, era obligado diseñar la propia reconstrucción emocional, una vida nueva, que no olvidaba la antigua, pero que se llenaba también de contenido y alivio.

El exilio les había obligado a enfrentarse a un sinnúmero de emociones. En un comienzo en los exiliados se advierte rabia y desazón, también incertidumbre, miedo y bloqueo. Llegado al lugar donde el exilio iba a desarrollarse y superados los requisitos legales que todo desplazamiento imponía en forma de visados y permisos, el desarraigo del emigrado, el vértigo ante lo desconocido, se mezclaba con las primeras nostalgias, la inquietud por la falta de noticias de los que se quedaron en España y las preguntas sobre cuánto tiempo habría uno de quedarse así y allí. Una vez asumido que se tenía donde estar, es el choque con las costumbres del lugar de acogida lo que el exiliado expresa como emoción esencial pero también el rechazo y la apreciación de las diferencias a las que se halla un lado positivo pero que también provocan cansancio y excitación. Con el tiempo, el exiliado empieza a ser consciente de que otros tantos se encuentran en situación pareja y compara, identifica, asume o niega lo que comparte con los demás exiliados. En procesos de exilios tan largos como ofrece el ejemplo español, se desplegaron vidas enteras en tiempo, dedicación profesional y desarrollo familiar. Y tocó, no quedaba otra, replantear las metas y los objetivos. Con caras diversas, se ve en Salinas, en Castro y en De los Ríos, llegó un éxito que consistió, generalmente, en buenos destinos profesionales, la consecución de un bienestar económico para la familia y la integración de ésta, en especial de los hijos, por la vía formativa. Ese éxito no dejó de tener nunca un sabor agridulce. Culminaba un

\footnotetext{
101 SALINAS, Pedro, Obras Completas III..., p. 1066.
} 
esfuerzo enorme de superación y adaptación que permitía que el exiliado se reconociera como el profesional que era pudiendo dedicar su tiempo a las tareas con las que siempre estuvo comprometido. Había reconducido su carrera profesional y personal sin salirse en exceso de lo que había pensado para sí. En un lugar nunca imaginado y fuera de sus escenarios cotidianos, el exiliado, pasado el tiempo, pudo observar que su vida había conseguido orientarse y disfrutarse... aunque siempre quedara la misma nostalgia con la que salió al exilio y las mismas ganas de colaborar en que las circunstancias que lo provocaron acabaran. Y más agridulce fue esa emoción al comprobar que su suerte había sido mejor que la de quienes optaron por quedarse.

Todo ello hay, y aún mucho más, en un proceso exílico, como estas notas permiten saber en los casos de De los Ríos, Salinas y Castro. 